\title{
Comparison of Species and Cell-Type Differences in Fraction Unbound of Liver Tissues, Hepatocytes, and Cell Lines ${ }^{\mathrm{S}}$
}

\author{
Keith Riccardi, Sangwoo Ryu, Jian Lin, Phillip Yates, David Tess, Rui Li, Dhirender Singh, ${ }^{1}$ \\ Brian R. Holder, ${ }^{2}$ Brendon Kapinos, George Chang, and Li Di \\ Pharmacokinetics, Dynamics and Metabolism, Pfizer Inc., Groton, Connecticut (K.R., S.R., J.L., D.S., B.R.H., B.K., G.C., L.D.); \\ and Early Clinical Development (P.Y.), and Pharmacokinetics, Dynamics and Metabolism (D.T., R.L.), Pfizer Inc., Cambridge, \\ Massachusetts
}

Received October 23, 2017; accepted January 24, 2018

\section{ABSTRACT}

Fraction unbound $\left(f_{\mathrm{u}}\right)$ of liver tissue, hepatocytes, and other cell types is an essential parameter used to estimate unbound liver drug concentration and intracellular free drug concentration. $f_{\mathrm{u}, \text { liver }}$ and $f_{\mathrm{u}, \text { cell }}$ are frequently measured in multiple species and cell types in drug discovery and development for various applications. A comparison study of 12 matrices for $f_{\mathrm{u}, \text { liver }}$ and $f_{\mathrm{u}, \text { cell }}$ of hepatocytes in five different species (mouse, rat, dog, monkey, and human), as well as $f_{\mathrm{u}, \text { cell }}$ of Huh7 and human embryonic kidney 293 cell lines, was conducted for 22 structurally diverse compounds with the equilibrium dialysis method. Using an average bioequivalence approach, our results show that the average difference in binding to liver tissue, hepatocytes, or different cell types was within 2-fold of that of the rat $f_{u, l i v e r}$. Therefore, we recommend using rat $f_{\mathrm{u} \text {,iver }}$ as a surrogate for liver binding in other species and cell types in drug discovery. This strategy offers the potential to simplify binding studies and reduce cost, thereby enabling a more effective and practical determination of $f_{\mathrm{u}}$ for liver tissues, hepatocytes, and other cell types. In addition, $f_{u}$ under hepatocyte stability incubation conditions should not be confused with $f_{\mathrm{u}, \text { cell, }}$, as one is a diluted $f_{\mathrm{u}}$ and the other is an undiluted $f_{\mathrm{u}}$. Cell density also plays a critical role in the accurate measurement of $f_{\mathrm{u}, \text { cell- }}$

\section{Introduction}

For disease targets residing in the tissues (e.g., liver, brain, or muscle), free drug concentrations in tissues are critical for in vivo efficacy and for the development of pharmacokinetics/pharmacodynamics relationships (Smith et al., 2010). The fraction unbound $\left(f_{\mathrm{u}}\right)$ of tissues is essential for the determination of in vivo free drug concentrations in the tissues, as total tissue drug concentrations are usually measured in vivo, and free drug concentration is then calculated by multiplying total drug concentration with $f_{\mathrm{u}}$ (i.e., free drug concentration $=$ total drug concentration $\times f_{\mathrm{u}}$ ). The liver is an important organ for a number of therapeutic targets, such as diabetes, dyslipidemia, obesity, and nonalcoholic steatohepatitis. Recent strategies for liver targeting by utilizing liver-specific uptake transporters [e.g., organic anion-transporting polypeptide (OATP) 1B1 and OATP1B3] have shown promise in enhancing efficacy in the liver and minimizing side effects in peripheral tissues (Oballa et al., 2011; Pfefferkorn, 2013; Tu et al., 2013). Even for compounds that are not liver targeting by design, their clearance and disposition can still be mediated by transporters ( $\mathrm{Li}$ et al., 2014). For these cases, liver-free drug concentration might not be the same as plasma-free drug concentration due to the impact of transporters

\footnotetext{
${ }^{1}$ Current affiliation: Navinta LLC, Ewing, New Jersey.

${ }^{2}$ Current affiliation: PerkinElmer, Shelton, Connecticut.

https://doi.org/10.1124/dmd.117.079152.

SThis article has supplemental material available at dmd.aspetjournals.org.
}

(Pfefferkorn et al., 2012). Therefore, an accurate determination of $f_{\mathrm{u}}$ of liver tissue $\left(f_{\mathrm{u} \text {,liver }}\right)$ is important to estimate free liver drug concentration. With increasing knowledge of the effects of hepatobiliary influx and efflux transporters on drug disposition, our ability to predict free liver drug concentration is critical for assessing efficacy, therapeutic index, the potential for drug-drug interactions, and toxicity. For in vitro cellbased assays, such as metabolic stability, induction, inhibition, and pharmacological assays, $f_{\mathrm{u}}$ measurements of hepatocytes or other cell types $\left[f_{\mathrm{u}}\right.$ of cells $\left.\left(f_{\mathrm{u}, \mathrm{cell}}\right)\right]$ allows for the determination of intracellular free drug concentration (Mateus et al., 2013; Riccardi et al., 2016, 2017). Intracellular free drug concentration, rather than nominal concentration, is most relevant for compounds with intracellular accumulation or exclusion to develop in vitro-in vivo correlations for human translation and to understand the in vitro absorption, distribution, metabolism, excretion, and toxicity and pharmacology endpoints (Riccardi et al., 2016, 2017; Mateus et al., 2017; Riede et al., 2017; Sun et al., 2017). Using intracellular free drug concentration, the unbound partition coefficient $\left(\mathrm{K}_{\text {puu }}\right)$ can be determined and used to derive intrinsic activity for in vitro cell-based assays (e.g., $\mathrm{CL}_{\text {int }}=\mathrm{CL}_{\text {int }}{ }^{\prime} / \mathrm{K}_{\text {puu }}, \mathrm{EC}_{50}=\mathrm{EC}_{50}{ }^{\prime} \times \mathrm{K}_{\text {puu }}, \mathrm{IC}_{50}=$ $\mathrm{IC}_{50}{ }^{\prime} \times \mathrm{K}_{\text {puu }}$, where $\mathrm{CL}_{\text {int }}$ is intrinsic clearance, $\mathrm{CL}_{\text {int }}{ }^{\prime}$ is apparent intrinsic clearance, $\mathrm{EC}_{50}{ }^{\prime}$ is apparent $\mathrm{EC}_{50}$, and $\mathrm{IC}_{50}{ }^{\prime}$ is apparent $\mathrm{IC}_{50}$ ).

Binding to liver tissues and cells (e.g., hepatocytes, Huh7, and HEK293 ) is routinely measured in various species and cell types matching the corresponding in vivo and in vitro studies, partly because species and cell type-dependent binding is mostly unexplored. Recent studies of $f_{\mathrm{u}, \text { cell }}$ in HEK-293 cells have shown good correlation between human and

ABBREVIATIONS: ACN, acetonitrile; $\mathrm{Cl}$, confidence interval; $\mathrm{D}$, dilution factor; DMEM, Dulbecco's modified eagles medium; $f_{\mathrm{u}}$, fraction unbound; $f_{\mathrm{u}, \text { cell }}$, fraction unbound of cells; $f_{\mathrm{u}, \mathrm{d}}$, diluted fraction unbound; $f_{\mathrm{u}, \mathrm{inc}}$, fraction unbound under incubation conditions; $f_{\mathrm{u}, \text { liver }}$, fraction unbound of liver tissues; HEK-293, human embryonic kidney 293; HPLC, high-performance liquid chromatography; Huh7, human hepatocyte-derived carcinoma cell line; IS, internal standard; $\mathrm{K}_{\mathrm{puu}}$ unbound partition coefficient; LC-MS/MS liquid chromatography coupled with tandem mass spectrometry; OATP, organic anion-transporting polypeptide; PBS, phosphate-buffered saline; TOST, two one-sided test. 
TABLE 1

Cell diameters and dilution factors of cell homogenates

\begin{tabular}{|c|c|c|c|}
\hline Cells & Diameter \pm S.D. & Cell Volume & D at 50 Million Cells $/ \mathrm{ml}$ \\
\hline & $\mu \mathrm{m}$ & $\mu \mathrm{l} /$ million cells & \\
\hline Mouse hepatocyte & $19.7 \pm 1.5$ & 4.00 & 5.00 \\
\hline Rat hepatocyte & $19.1 \pm 0.74$ & 3.65 & 5.48 \\
\hline Dog hepatocyte & $15.8 \pm 0.93$ & 2.07 & 9.69 \\
\hline Monkey hepatocyte & $15.0 \pm 0.64$ & 1.77 & 11.3 \\
\hline Human hepatocyte & $17.3 \pm 1.5$ & 2.71 & 7.38 \\
\hline Huh7 cells & $14.1 \pm 0.33$ & 1.47 & 13.6 \\
\hline HEK-293 cells & $14.3 \pm 0.83$ & 1.53 & 13.1 \\
\hline
\end{tabular}

rat hepatocyte binding after a 4-fold to 6-fold correction of dilution factor (D), defined as the total suspension volume divided by cell volume (Mateus et al., 2013). This suggested that binding might be independent of cell type and species with correction factors for the concentrations of the binding components in cell and tissue homogenates. Furthermore, it has also been reported that binding to phospholipids is mostly responsible for liver microsomal binding (Margolis and Obach, 2003), which suggests that binding to hepatocytes is likely to be species and/or cell type independent. Plasma protein binding has been shown to be species dependent due to specific binding to certain plasma proteins (Kratochwil et al., 2004; Di and Kerns, 2016). In contrast, binding to brain tissue has been reported to be independent of species as it is mostly driven by nonspecific binding to phospholipids in brain tissue (Summerfield et al., 2008; Read and Braggio, 2010; Di et al., 2011). For exploration, it would be very useful to determine whether binding to liver tissues, hepatocytes, and various cells that are commonly used in drug discovery are species and cell type independent. Herein, we discuss the evaluation of $f_{\mathrm{u} \text {,liver }}$ and $f_{\mathrm{u} \text {,cell }}$ in multiple species for 22 structurally diverse compounds using the equilibrium dialysis method. Overall, these efforts will help to determine whether liver binding from a single species can be used to represent binding for all common species and cell types. The anticipated outcome of this study is geared toward the simplification of liver tissue and cell-binding studies to inform free tissue and intracellular free drug concentrations with the added benefit of reducing costs in drug discovery.

\section{Materials and Methods}

Materials. Liver tissue of CD-1 mouse, cynomolgus monkey, and hepatocytes from all species were purchased from BioreclamationIVT, LLC (Hicksville, NY). Human liver tissue was obtained from Analytical Biologic Services Inc. (Wilmington, DE). Wistar Han rat liver and beagle dog liver were obtained in-house at Pfizer Research and Development (Groton, CT). All tissue samples were collected from animals in accordance with regulations and established guidelines including review and approval by an Institutional Animal Care and Use Committee. HEK-293 and Huh7 cells were purchased from American Type Culture Collection (Manassas, VA). Test compounds were obtained from Pfizer Global Material Management or purchased from Sigma-Aldrich (St. Louis, MO). Dulbecco's modified Eagles medium (DMEM), penicillin streptomycin, sodium pyruvate, and trypsin-EDTA were obtained from Life Technologies (Carlsbad, CA). Fetal bovine serum and all HPLC solvents were purchased from SigmaAldrich, and HEPES was purchased from Lonza (Walkersville, MD). The 96-well equilibrium dialysis (HTD 96) device and cellulose membranes with molecular mass cutoff of 12-14 kDa were obtained from HTDialysis, LLC (Gales Ferry, CT). Microtiter 96-deep well plates with a $1.2 \mathrm{ml}$ capacity were obtained from Thermo Fisher Scientific (Waltham, MA), and T175 flasks were obtained from Corning Inc. (Corning, NY).

Cell Culture for HEK-293 and Huh7 Cell Lines. HEK-293 and Huh7 cells were cultured using DMEM, supplemented with $10 \%$ fetal bovine serum, $25 \mathrm{mM}$ HEPES, $1 \%$ penicillin streptomycin, and $1 \%$ sodium pyruvate. Cells were trypsinized using trypsin-EDTA and passaged either at 1:10 for HEK-293 cells or

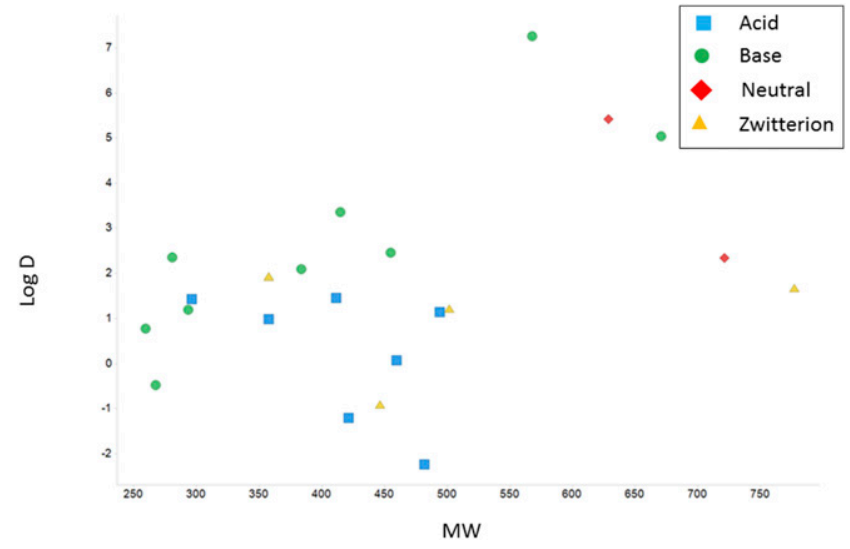

Fig. 1. Physicochemical properties of the 22 test compounds. MW, molecular weight.

1:5 for Huh7 cells into T175 flasks containing $25 \mathrm{ml}$ of DMEM media with supplements. Cells were incubated at $37^{\circ} \mathrm{C} / 5 \% \quad \mathrm{CO}_{2} / 75 \%$ relative humidity for 4 days to reach confluence. Cell passages ranging from 10 to 25 were used for binding studies.

Preparation of Liver Tissue, Hepatocytes, and Cell Homogenates. Liver tissue samples (nonperfused) were rinsed with water to wash away the residual blood after harvest and subsequently were dried with paper towel. The procedure has been effective in removing blood from the liver tissue. Tissue samples were frozen at $-20^{\circ} \mathrm{C}$ before use. Dulbecco's phosphate-buffered saline (PBS, without $\mathrm{Ca}^{2+}$ or $\mathrm{Mg}^{2+}$; VWR, Bridgeport, $\left.\mathrm{NJ}\right)$ in four times the liver tissue weight (v/w) was added to the preweighted liver tissues $(\mathrm{D}=5)$. The liver tissues were homogenized in PBS using a TH tissue homogenizer (Omni International, Kennesaw, GA) with a $7 \times 110 \mathrm{~mm}$ tip at high speed for 30 -second pulses. The liver homogenate suspensions were aliquoted into small portions and frozen at $-20^{\circ} \mathrm{C}$ for future use. The liver suspensions were homogenized again before each dialysis experiment to ensure the formation of a homogeneous suspension. For hepatocytes and cells, a cell density of 40-60 million cells $/ \mathrm{ml}$ suspension was prepared in PBS and homogenized as discussed above. Diameters of the cells were measured using Vi-CELL (Beckman Coulter, Danvers, MA) at an average cell density of $2.5 \times 10^{6}$ cells $/ \mathrm{ml}$. Cell volumes were calculated using cell diameters assuming a spherical shape. $\mathrm{D}$ was calculated by dividing the total cell suspension volume by the cell volume (Table 1).

Equilibrium Dialysis. The dialysis membranes were prepared prior to experimental setup. The cellulose membranes (molecular weight cutoff, 12-14 $\mathrm{kDa}$ ) were immersed in deionized water for 15 minutes, followed by 15 minutes in $30 \% \mathrm{EtOH} /$ deionized water, then at least 15 minutes or overnight in PBS. The equilibrium dialysis device (HTD 96) was assembled according to manufacturer instructions (http://www.htdialysis.com/). Dimethylsulfoxide stock solutions of test compounds were prepared at $200 \mu \mathrm{M}$, added in a 1:100 ratio to liver or cell homogenates, and mixed thoroughly with an eight-channel pipettor (Eppendorf; VWR, Radnor, PA). The final compound concentration for the equilibrium dialysis experiments was $2 \mu \mathrm{M}$, containing $1 \%$ dimethylsulfoxide. A $150 \mu \mathrm{l}$ aliquot of tissue or cell homogenates spiked with $2 \mu \mathrm{M}$ test compound was added to one side of the dialysis chamber (donor), and $150 \mu \mathrm{l}$ of PBS was added to the other side of the dialysis membrane (receiver). Each compound was assessed in quadruplicate. Before and after incubation, an aliquot of $15 \mu \mathrm{l}$ of homogenates spiked with $2 \mu \mathrm{M}$ compounds was added to a 96-deep well plate containing $45 \mu \mathrm{l}$ of PBS and mixed well. Two hundred microliters of cold acetonitrile (ACN) with mass spectrometry internal standard [IS (a cocktail of $0.5 \mathrm{ng} / \mathrm{ml}$ tolbutamide and $5 \mathrm{ng} / \mathrm{ml}$ terfenadine)] was added to precipitate the proteins/tissues. These samples were used as time zero to assess recovery of the assay and compound stability during incubation. The HTD 96 equilibrium dialysis device was covered with a Breathe Easy gas-permeable membrane (Sigma-Aldrich), placed on an orbital shaker (VWR) at $200 \mathrm{rpm}$, and incubated for 6 hours in a humidified ( $75 \%$ relative humidity) incubator at $37^{\circ} \mathrm{C}$ with $5 \% \mathrm{CO}_{2} / 95 \%$ air. At the end of the incubation, $15 \mu \mathrm{l}$ of homogenate samples from the donor wells were taken and added to a 96-deep well plate containing $45 \mu \mathrm{l}$ of PBS and mixed well. Aliquots of $45 \mu 1$ dialyzed PBS were taken from the receiver wells and added to $15 \mu \mathrm{l}$ of blank homogenates to achieve matrix-match and mixed 


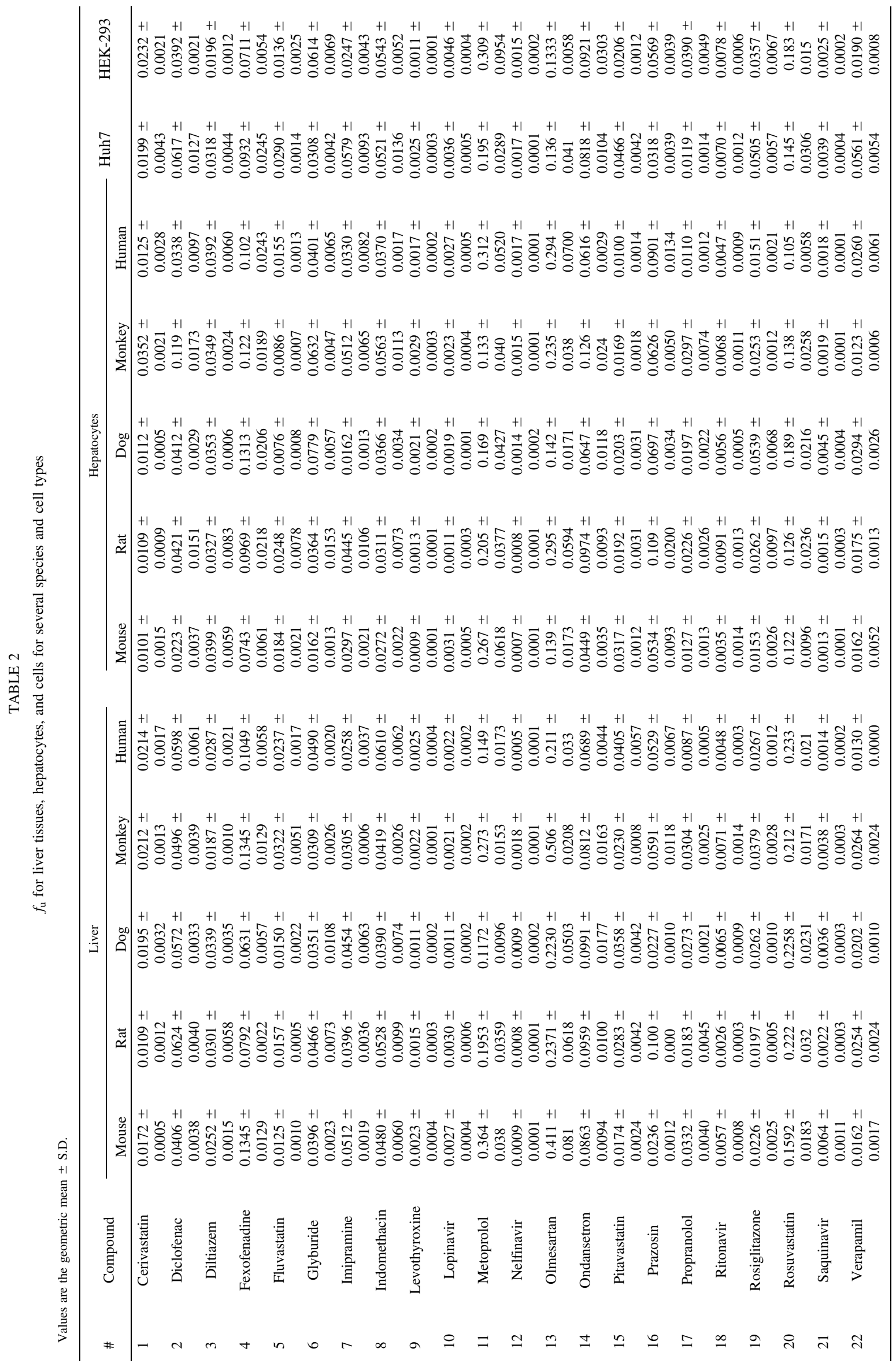

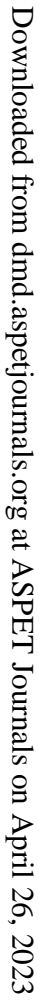




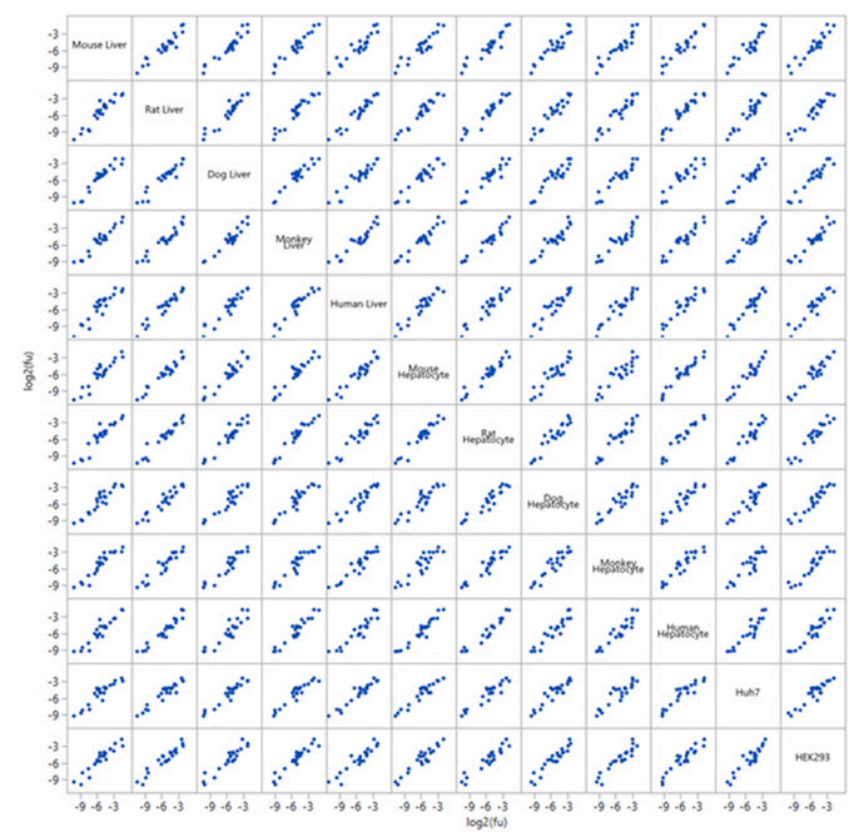

Fig. 2. Pairwise $f_{\mathrm{u}}$ comparisons for various species in liver tissues, hepatocytes, and two cell lines. Sample $f_{\mathrm{u}}$ estimates of 22 compounds across 12 matrices, $\log _{2}$ scale, suggests approximate intermatrix agreement.

well. Two hundred microliters of cold ACN with IS was added to precipitate the proteins/tissues. The plates were sealed and mixed with a vortex mixer (VWR) for 1 minute, then centrifuged at 3000 rpm (Beckman Coulter, Fullerton, CA) at room temperature for 5 minutes. The supernatant was transferred to a new 96-deep well plate, dried down, reconstituted, and subsequently analyzed using LC-MS/MS.

LC-MS/MS Analysis. A typical LC-MS/MS method is described here, and equivalent methods were used depending on sample properties. Samples were reconstituted in HPLC grade water/ACN, 50:50 (v/v), vortexed and centrifuged. A $10-\mu 1$ aliquot of supernatant was injected onto a LC-MS/MS system using a CTC PAL Autosampler (LEAP Technologies, Morrisville, NC) equipped with a model 1290 binary pump (Agilent, Santa Clara, CA). An ACQUITY UPLC column $(\mathrm{BEH}$ C18, 1.7, $50 \times 2.1 \mathrm{~mm}$; Waters, Milford, MA) was used. A linear HPLC gradient was performed from $95 \%$ mobile phase A $(0.1 \%$ formic acid in water) to $95 \%$ mobile phase $\mathrm{B}(0.1 \%$ formic acid in $\mathrm{ACN})$ over 1.1 minutes at a flow rate of $0.5 \mathrm{ml} / \mathrm{min}$ to elute the compounds. A triple quadrupole 5500 or 6500 mass spectrometer (Sciex, Foster City, CA) equipped with a turbo ion spray probe and IonDrive Turbo $\mathrm{V}$ source was operated in mixed polarity mode. Multiple reaction monitoring was used to detect ion transitions of analytes, along with terfenadine (ESI+) and tolbutamide (ESI-) as ISs. Analyst version 1.6.2 (Applied Biosystems, Foster City, CA) was used for data acquisition, and MultiQuant version 3.0.2 (Applied Biosystems) was applied for quantitation. All calculations were based on area ratios (analyte peak area/IS peak area).

Calculation of $f_{\mathrm{u}}$, Recovery, and Stability. Diluted $f_{\mathrm{u}}\left(f_{\mathrm{u}, \mathrm{d}}\right)$ values of liver tissues and cells were calculated using eq. 1. The area ratios of test compound to IS in receiver and donor wells were determined using LC-MS/MS corrected to account for sampling volume differences. The undiluted $f_{\mathrm{u}}$ of liver tissues and cells was obtained using eq. 2 (Riccardi et al., 2016). Recovery and stability were calculated using eqs. 3 and 4 , respectively.

$$
\begin{aligned}
& \text { Diluted } f_{u, d}=\frac{\text { Receiver Area Ratio }}{\text { Donor Area Ratio }} \\
& \text { Undiluted } f_{u}=\frac{1 / D}{\left.\left(\left(1 / f_{u, d}\right)-1\right)+1 / D\right)} \\
& \% \text { Recovery }=\frac{\text { Donor Area Ratio }+ \text { Receiver Area Ratio }}{\text { Donor Area Ratio at Time Zero }} \times 100 \% \\
& \text { Stability as } \% \text { Remaining }=\frac{\text { Area Ratio at Six Hour }}{\text { Area Ratio at Zero Hour }} \times 100 \%
\end{aligned}
$$

Statistical Data Analysis. The $f_{\mathrm{u}}$ quadruplicate distributions were evaluated using standard data analysis methods (Montgomery, 2001) to explore suitable data transformations. Specifically, the log transformation is useful for distributions that are log-normally distributed, subject to proportional errors, have a constant $\mathrm{CV}$, or for variances proportional to the mean squared. To compare the $f_{\mathrm{u}}$ values for the different species and cell types, the log transformation was applied to the geometric mean, a standard summary statistic for skewed assay data, per compound after the quadruplicate evaluation. All statistical inference, excluding standard summary statistics, was performed on the $\log _{2}$ scale. The $\log _{2}$ scale facilitates comparing $f_{\mathrm{u}}$ ratios per compound across tissues on an additive scale. Pearson correlation coefficient estimates are provided for each pair of species and

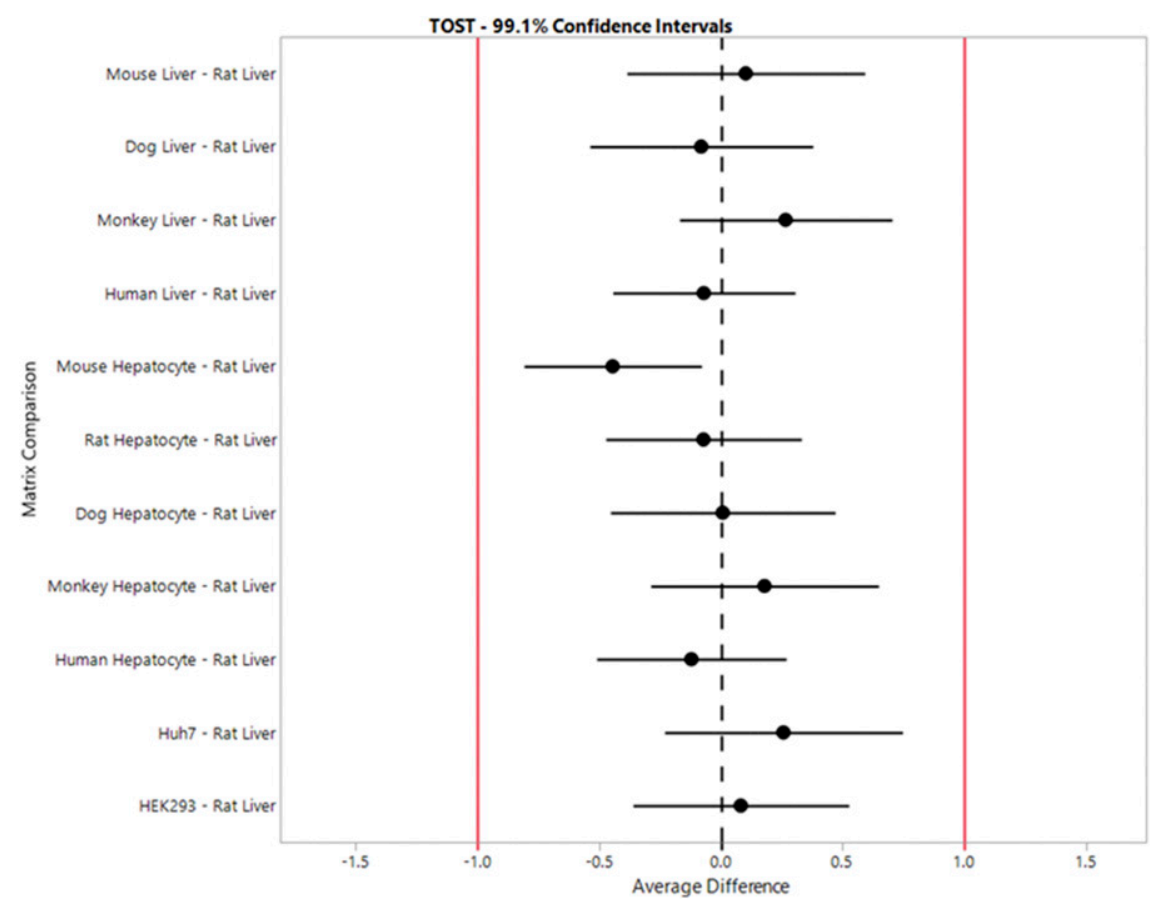

Fig. 3. Average bioequivalence comparison of $f_{\mathrm{u}, \text { liver }}$ or $f_{\mathrm{u}, \text { cell. }}$. Bonferroni-adjusted CIs for the average $f_{\mathrm{u}}$ matrix difference relative to rat liver $f_{\mathrm{u}}$ on the $\log _{2}$ scale for 22 compounds. Average equivalence is declared if the $99.1 \%$ CI for the average difference is entirely contained in the \pm 1 interval (i.e., within \pm 2 -fold on the original scale). 


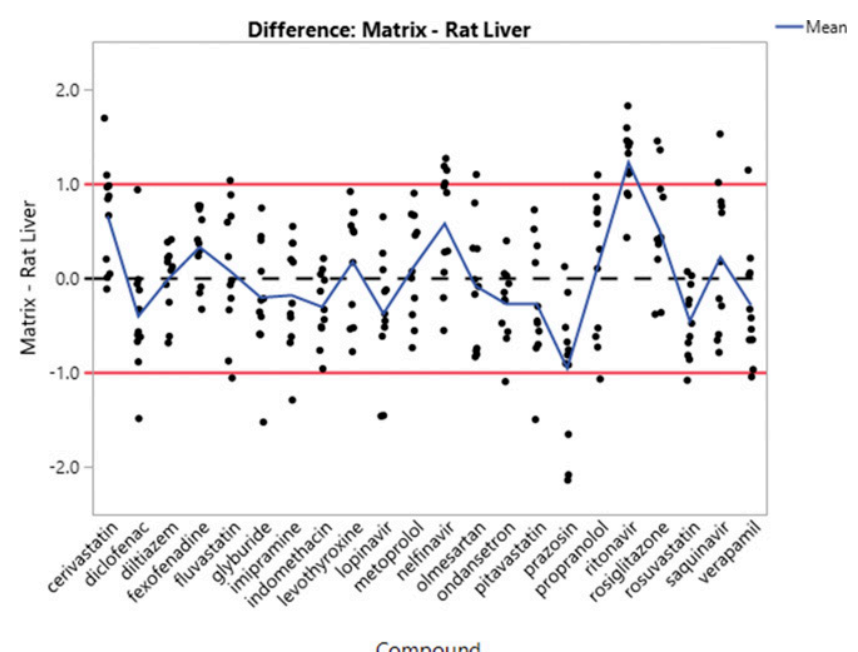

Compound

Fig. 4. $f_{\mathrm{u}}$ matrix differences relative to rat liver per compound. $f_{\mathrm{u}}$ values for each matrix minus the corresponding rat liver $f_{\mathrm{u}}, \log _{2}$ scale, per compound.

cell-type $f_{\mathrm{u}}$ values. To assess the comparability of the $f_{\mathrm{u}}$ determinations, the two one-sided test (TOST) average bioequivalence procedure outlined in Walker and Nowacki (2011) was used. In standard bioequivalence test settings, the null hypothesis assumes that the average difference between two tissues is larger than a prespecified value; the research hypothesis is that the two tissue averages are equivalent relative to an acceptable difference margin. Here, the margin of equivalence was prespecified at \pm 2 -fold $\left[ \pm 1\right.$ for a $\log _{2}(x)-\log _{2}(y)$ difference and to conveniently aide the data interpretation] from the reference tissue $f_{\mathrm{u}}$. The rat liver $f_{\mathrm{u}}$ estimate was prespecified as the reference tissue. Normal q-q plots were used to assess the normality of the $\log _{2}\left(f_{\mathrm{u}}\right)$ compound estimates for each tissue. In standard TOST equivalence settings, a $90 \%$ confidence interval (CI) for the average difference is computed. Due to the 11 tissue-relative comparisons performed, we applied the Bonferroni correction to retain a family-wise error rate of 0.05 . If the adjusted $99.1 \%$ CI for an intertissue comparison was contained entirely within the prespecified margin, the two average $f_{\mathrm{u}}$ estimates are declared to be equivalent. JMP version 13.0.0 (SAS Institute, Cary, NC) was used for the statistical analyses.

\section{Results}

A set of 22 structurally diverse compounds were used to evaluate the $f_{\mathrm{u}}$ dependency on species and cell type using 12 matrices. The physicochemical properties of the test compounds are shown in Fig. 1. The molecular mass of the compounds ranged from 200 to $800 \mathrm{Da}$ and $\log \mathrm{D}_{7.4}$ (lipophilicity) values ranged from -2 to 7 . Acids, bases, neutrals, and zwitterions were included in the test set. The $f_{\mathrm{u} \text {,liver }}$ values of five species (i.e., mouse, rat, dog, monkey, and human) were determined using equilibrium dialysis method with liver homogenates. In addition, $f_{\mathrm{u} \text {,cell }}$ values of hepatocytes for five species (mouse, rat, dog, monkey, and human), Huh7 cells, and HEK-293 cells were measured using cell homogenates at cell densities of 40-60 million cells $/ \mathrm{ml}$. Huh7 cells were included because it is a hepatocyte-derived cell line with fast growing characteristics and could potentially be used to substitute for expensive hepatocytes in binding studies. Drug transporters (e.g., OATPs, organic anion transporters, and organic cation transporters) are frequently transfected and expressed in HEK-293 cells, and the $f_{\mathrm{u}, \mathrm{cell}}$ of HEK-293 cells is often measured to obtain intracellular free drug concentration using the binding method (Mateus et al., 2013; Riccardi et al., 2016). Thus, HEK-293 cells were included in the study for comparison purposes. The geometric means of the $f_{\mathrm{u}}$ quadruplicates along with their S.D.s for each matrix are summarized in Table 2. The $f_{\mathrm{u}}$ values range from 0.00052 to 0.51 , spanning three $\log _{10}$ units. The average $\mathrm{CV}$ for the quadruplicates is $12.5 \%$, suggesting good
TABLE 3

Comparison of $f_{\mathrm{u}, \mathrm{cell}}$ and $f_{\mathrm{u} \text {,inc }}$

\begin{tabular}{|c|c|c|}
\hline Characteristics & $f_{\mathrm{u}, \mathrm{cell}}$ & $f_{\mathrm{u}, \mathrm{inc}}$ \\
\hline $\begin{array}{l}\text { Influencing } \\
\text { factors }\end{array}$ & $\begin{array}{l}\text { Intrinsic property of a } \\
\text { compound }\end{array}$ & $\begin{array}{l}\text { Compound property and } \\
\text { incubation conditions }\end{array}$ \\
\hline Cell density & Independent of cell density & $\begin{array}{c}\text { Decreases with increasing cell } \\
\text { density }\end{array}$ \\
\hline Measurement & $\begin{array}{l}\text { Cell homogenate at high cell } \\
\text { density (e.g., } 50 \text { million } \\
\text { cells } / \mathrm{ml})\end{array}$ & $\begin{array}{l}\text { Cell homogenate at low cell } \\
\text { density under incubation } \\
\text { conditions } \\
\text { (e.g., } 0.5-2 \text { million cells } / \mathrm{ml} \text { ) }\end{array}$ \\
\hline $\mathrm{D}$ & $\begin{array}{l}\sim 8 \text { for human hepatocytes at } \\
50 \text { million cells } / \mathrm{ml}\end{array}$ & $\begin{array}{c}\sim 800 \text { for human hepatocytes at } \\
0.5 \text { million cells } / \mathrm{ml}\end{array}$ \\
\hline Definition & Undiluted $f_{\mathrm{u}}$ & Diluted $f_{\mathrm{u}, \mathrm{d}}$ \\
\hline Values & $\begin{array}{l}\text { Generally low, similar to } f_{\mathrm{u}, \text { liver }} \\
\text { for hepatocytes }\end{array}$ & $\begin{array}{l}\text { Generally high, similar to } f_{\mathrm{u} \text {,mic }} \\
\text { with comparable protein level }\end{array}$ \\
\hline
\end{tabular}

$f_{\mathrm{u}, \mathrm{mic}}, f_{\mathrm{u}}$ in liver microsomes.

reproducibility of the data across the entire $f_{\mathrm{u}}$ range. This result is similar to previous findings from our laboratory (Riccardi et al., 2015) where it has been demonstrated that the $\mathrm{CV}$ does not depend on the magnitude of the $f_{\mathrm{u}}$ (Supplemental Fig. 1) for binding measurements using the equilibrium dialysis assay. This indicates that our $f_{\mathrm{u}}$ determination has comparable precision across the entire $f_{\mathrm{u}}$ range (Riccardi et al., 2015). The $f_{\mathrm{u}}$ comparisons for each pair of matrices for the 22 compounds are plotted in Fig. 2. The correlation coefficients among all the comparisons are close to unity and range from 0.90 to 0.97 (Supplemental Table 1), indicating a strong correlation between $f_{\mathrm{u}}$ determinations per compound across the different species and cell types. These results suggest that one could use a single species/matrix (e.g., rat liver) as a surrogate for $f_{\mathrm{u}, \text { liver }}$ and $f_{\mathrm{u}, \text { cell }}$ values of other species. Normal q-q plots of compound-level $\log _{2}\left(f_{\mathrm{u}}\right)$ estimates per matrix suggest that these data are approximately normally distributed (Supplemental Fig. 2). The TOST equivalence test was conducted relative to the rat $f_{\mathrm{u} \text {,liver }}$ values for each matrix, and the results are shown in Fig. 3. All of the $99.1 \%$ adjusted CIs are contained in the \pm 1 interval, suggesting average equivalence for each matrix relative to rat $f_{\mathrm{u}, \text { liver }}$ values for this set of 22 compounds. This suggests that $f_{\mathrm{u} \text {,liver }}$ and $f_{\mathrm{u} \text {,cell }}$ values are within an acceptable margin of error across commonly used species and cell types. Based on these results, we propose that rat $f_{\mathrm{u} \text {,liver }}$ be used as a surrogate for determinations of $f_{\mathrm{u} \text {,liver }}$ and $f_{\mathrm{u}, \text { cell }}$ values for other species and cell types in drug discovery. The differences between rat $f_{\mathrm{u} \text {,liver }}$ and the other matrices were also examined for compound dependencies. Despite the intrinsic experimental uncertainty of the rat $f_{\mathrm{u}, \mathrm{liver}}$ estimate, the other $f_{\mathrm{u}}$ matrix estimates for a given compound were generally within \pm 2 -fold (Fig. 4). Across all of the 22 compounds tested, only one compound, ritonavir, resulted in an average $f_{\mathrm{u}}$ difference greater than 2-fold. This suggests that under the current equilibrium dialysis method, rat liver serves as a suitable matrix for $f_{\mathrm{u}}$ assessments that could be adapted for most drug discovery compounds.

\section{Discussion}

This study of a diverse set of 22 compounds and with a wide range of $f_{\mathrm{u}}$ values in 12 different matrices showed that $f_{\mathrm{u} \text {,liver }}$ and $f_{\mathrm{u}, \text { cell }}$ values were independent of the species and cell types commonly used in drug discovery. To the best of our knowledge, this is the first study comparing species differences in the binding of liver tissues, hepatocytes, and other cell types. We propose that rat $f_{\mathrm{u} \text {,liver }}$ be used as a surrogate for $f_{\mathrm{u}}$, liver and $f_{\mathrm{u} \text {,cell }}$ for other species and cell types. This offers the potential to greatly simplify binding studies to enable effective determination of free liver drug concentrations in multiple species, intracellular free drug concentrations in cell-based assays, and in vitro and in vivo $\mathrm{K}_{\text {puu }}$. Our 
1 million cells/mL Dilution factor 370
10 million cells $/ \mathrm{mL}$ Dilution factor 38
50 million cells $/ \mathrm{mL}$ Dilution factor 8
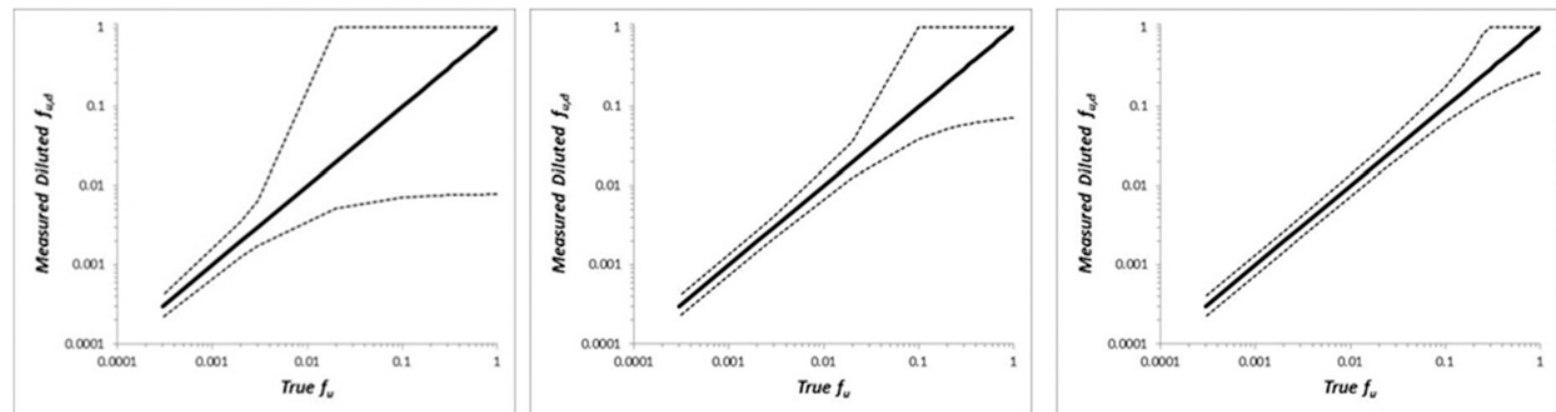

Fig. 5. Effect of cell density and D on undiluted $f_{\mathrm{u}}$. Assume that the human hepatocyte diameter is $17.3 \mu \mathrm{m}$ and the $\mathrm{CV}$ for $f_{\mathrm{u}, \mathrm{d}}$ measurement is $15 \%$. Dotted lines represent $95 \%$ CI. $f_{\mathrm{u}}$ values that can be accurately measured decreased with increased D or decreased in cell density.

findings are consistent with studies reported previously that binding to liver microsomes is mostly driven by nonspecific binding to phospholipids, which is species independent (Margolis and Obach, 2003). The results are also in good agreement with the observation that $f_{\mathrm{u}}$ values of hepatocytes correlate well with those from HEK-293 cells (Mateus et al., 2013). Hepatocytes account for approximately $80 \%$ of the liver volume (Kmiec, 2001); therefore, the binding to liver tissue is expected to be similar to that of hepatocytes. Both $f_{\mathrm{u} \text {,liver }}$ and $f_{\mathrm{u} \text {,cell }}$ are mainly driven by nonspecific binding to phospholipids from cell membranes and liver tissues.

Plasma protein binding can be measured by using plasma directly without the need of any dilution. In contrast, tissues cannot be used directly for binding studies, and they are usually diluted with buffer and homogenized prior to binding experiments. Therefore, the $f_{\mathrm{u}, \mathrm{d}}$ is measured directly from experiments, and the undiluted $f_{\mathrm{u}}$ values are derived using eq. 2 . For cell-binding $\left(f_{\mathrm{u} \text {,cell }}\right)$ measurements, it is slightly more complicated because it is often confused with fraction unbound under incubation conditions $\left(f_{\mathrm{u} \text {,inc }}\right)$ in cell-based assays (binding under incubation conditions with hepatocytes for metabolic stability or other experiments). The comparison of $f_{\mathrm{u}, \text { cell }}$ and $f_{\mathrm{u} \text {,inc }}$ is shown in Table $3 . f_{\mathrm{u}, \mathrm{cell}}$ is a measure of nonspecific binding of a compound in cell homogenates. It is considered to be an intrinsic property of a compound and is independent of cell density in the incubation when sufficient cells are used for measurement. $f_{\mathrm{u} \text {,inc, }}$ on the other hand, is dependent on the properties and cell density of a compound in the incubation. The higher the cell density, the lower the $f_{\mathrm{u} \text {,inc }}$ value. $f_{\mathrm{u}, \mathrm{cell}}$ is typically measured by using cell homogenates at high cell density (e.g., 50 million cells/ml; see Discussion below on the limitations of using a low cell density), and the value is usually much lower than that for $f_{\mathrm{u} \text {,inc }}$ but is similar to that for $f_{\mathrm{u} \text {,iver }} \cdot f_{\mathrm{u}, \text { cell }}$ can also be measured with whole cells at $4^{\circ} \mathrm{C}$ with the correction of the $\mathrm{pH}$-gradient effect (i.e., $f_{\mathrm{u} \text {,cell }}=1$ /partition coefficient at $4^{\circ} \mathrm{C}$ ), where active processes by transporters and enzymes and membrane potentials are essentially shut down at low temperature (Dipolo and Latorre, 1972; Fischbarg, 1972). The $f_{\mathrm{u} \text {,inc, }}$, on the contrary, is usually determined using cell homogenates or dead cells at lower cell densities, the same as under the incubation conditions for metabolic stability studies (e.g., 0.5-2 million cells $/ \mathrm{ml}) . f_{\mathrm{u}, \text { inc }}$ values are typically much higher than $f_{\mathrm{u}, \mathrm{cell}}$ values, but values are similar to those for $f_{\mathrm{u}}$ in liver microsomes at a comparable protein concentration. Since both $f_{\mathrm{u} \text {,cell }}$ and $f_{\mathrm{u} \text {,inc }}$ use cell homogenates for measuring binding, they are sometimes confused as being the same. $f_{\mathrm{u}, \mathrm{cell}}$ is an undiluted $f_{\mathrm{u}}$ and needs to be corrected once measured from diluted cell homogenates based on a D calculated from cell density and cell diameter (eq. 2). $f_{\mathrm{u} \text {,inc }}$ is an $f_{\mathrm{u}, \mathrm{d}}$, and it is measured directly from cell homogenates using incubation cell density and calculated using eq. 1. No

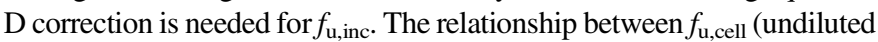
$\left.f_{\mathrm{u}}\right)$ and $f_{\mathrm{u}, \text { inc }}\left(f_{\mathrm{u}, \mathrm{d}}\right)$ can be described by eq. 2 only when cell density is high enough (i.e., low D), especially for weakly bound compounds.

The impact of cell density and $\mathrm{D}$ on undiluted $f_{\mathrm{u}}$ is shown in Fig. 5 and Table 4 . When the cell density is too low (D is too high), $f_{\mathrm{u}, \mathrm{d}}$ is too high for compounds that are not highly bound, and the variability can be very large when converted back to the undiluted $f_{\mathrm{u}}$ value. Therefore, in practice, to be able to accurately determine $f_{\mathrm{u} \text {,cell }}$ values, the measured $f_{\mathrm{u}, \mathrm{d}}$ value needs to be sufficiently low by selecting the appropriate cell density or D for tissue homogenates. This means that for highly bound compounds the cell density can be lower (e.g., 20 million cells/ml); but, for weakly bound compounds the cell density needs to be higher (e.g., 50 million cells $/ \mathrm{ml}$ ) to ensure an accurate conversion back to the undiluted $f_{\mathrm{u} \text {,cell. }}$. Cell density (or D) is important for measuring $f_{\mathrm{u}, \text { cell }}$. The observed differences in $f_{\mathrm{u}, \text { cell }}$

TABLE 4

Effects of cell density and D on undiluted $f$

\begin{tabular}{lrlllllllll}
\hline $\begin{array}{c}\text { Cell Density } \\
\text { million cells/ml }\end{array}$ & $\mathrm{D}$ & 0.01 & 0.05 & 0.1 & 0.3 & 0.5 & 0.7 & 0.9 & 0.99 & True $f_{\mathrm{u}}$ \\
\hline 1 & 370 & 0.79 & 0.95 & 0.98 & 0.99 & 1.00 & 1.00 & 1.00 & 1.00 & Measured $f_{\mathrm{u}, \mathrm{d}}$ \\
2 & 186 & 0.65 & 0.91 & 0.95 & 0.99 & 0.99 & 1.00 & 1.00 & 1.00 & \\
5 & 75 & 0.43 & 0.80 & 0.89 & 0.97 & 0.99 & 0.99 & 1.00 & 1.00 & \\
10 & 38 & 0.28 & 0.67 & 0.81 & 0.94 & 0.97 & 0.99 & 1.00 & 1.00 & \\
20 & 19 & 0.16 & 0.50 & 0.68 & 0.89 & 0.95 & 0.98 & 0.99 & 1.00 & \\
50 & 8 & 0.07 & 0.30 & 0.47 & 0.77 & 0.89 & 0.95 & 0.99 & 1.00 & \\
100 & 5 & 0.05 & 0.21 & 0.36 & 0.68 & 0.83 & 0.92 & 0.98 & 1.00 & \\
200 & 3 & 0.03 & 0.14 & 0.25 & 0.56 & 0.75 & 0.88 & 0.96 & 1.00 & \\
1000 & 1 & 0.01 & 0.05 & 0.10 & 0.30 & 0.50 & 0.70 & 0.90 & 0.99 & \\
\hline
\end{tabular}

Assume that the cell diameter is $17.3 \mu \mathrm{m}$. 
between hepatocytes and HEK-293 cells in the previous study might be due to too high a D caused by a low cell density (Mateus et al., 2013). The cell density for measuring $f_{\mathrm{u} \text {,inc }}$ under hepatocyte stability conditions is usually too low to generate reliable $f_{\mathrm{u}, \text { cell }}$ values, although they are perfectly fine to be used to correct for unbound intrinsic clearance. This study also suggests that a single-species microsomal or hepatocyte binding (e.g., $f_{\mathrm{u} \text {,inc }}$ for rat) can be used as a surrogate for $f_{\text {u,inc }}$ for all species with adjustment for protein concentration, when correcting for unbound concentration in in vitro incubations.

This species and cell-type comparison study in liver tissue, hepatocytes, and two cell lines (Huh7 and HEK-293) showed that $f_{\mathrm{u} \text {,liver }}$ is species independent and is comparable with $f_{\mathrm{u} \text {,cell }}$ from different cell types. $f_{\mathrm{u} \text {,liver }}$ from a single species (e.g., rat) can be used as a surrogate for liver binding of other species as well as $f_{\mathrm{u} \text {,cell }}$ of various cell types. $f_{\mathrm{u}, \text { cell }}$ should not be confused with $f_{\mathrm{u} \text {,inc }}$ in hepatocytes. They are very different and are used for different applications. This study also suggests that $f_{\mathrm{u} \text {,inc }}$ with a single species (e.g., rat) can be used to replace $f_{\mathrm{u} \text {,inc }}$ for other species.

\section{Acknowledgments}

We thank Karen Atkinson for her help with database search efforts and Patrick Trapa for useful discussion.

\section{Authorship Contributions}

Participated in research design: Riccardi, Ryu, Lin, Yates, Tess, Li, Singh, Holder, Kapinos, Chang, and Di.

Conducted experiments: Riccardi, Ryu, Lin, Singh, Holder, and Kapinos.

Performed data analysis: Riccardi, Ryu, Lin, Yates, Tess, Singh, Holder, Kapinos, Chang, and Di.

Wrote or contributed to the writing of the manuscript: Riccardi, Ryu, Lin, Yates, Li, Holder, Chang, and Di.

\section{References}

Di L and Kerns EH (2016) Drug-Like Properties: Concepts, Structure Design, and Methods, Elsevier, London.

Di L, Umland JP, Chang G, Huang Y, Lin Z, Scott DO, Troutman MD, and Liston TE (2011) Species independence in brain tissue binding using brain homogenates. Drug Metab Dispos 39: $1270-1277$.

Dipolo R and Latorre R (1972) Effect of temperature on membrane potential and ionic fluxes in intact and dialysed barnacle muscle fibres. J Physiol 225:255-273.

Fischbarg J (1972) Ionic permeability changes as the basis of the thermal dependence of the resting potential in barnacle muscle fibres. $J$ Physiol 224:149-171.
Kmieć Z (2001) Cooperation of liver cells in health and disease. Adv Anat Embryol Cell Biol 161: III-XIII, 1-151.

Kratochwil NA, Huber W, Müller F, Kansy M, and Gerber PR (2004) Predicting plasma protein binding of drugs-revisited. Curr Opin Drug Discov Devel 7:507-512.

Li R, Barton HA, Yates PD, Ghosh A, Wolford AC, Riccardi KA, and Maurer TS (2014) A "middle-out" approach to human pharmacokinetic predictions for OATP substrates using physiologically-based pharmacokinetic modeling. J Pharmacokinet Pharmacodyn 41:197-209.

Margolis JM and Obach RS (2003) Impact of nonspecific binding to microsomes and phospholipid on the inhibition of cytochrome P4502D6: implications for relating in vitro inhibition data to in vivo drug interactions. Drug Metab Dispos 31:606-611.

Mateus A, Gordon LJ, Wayne GJ, Almqvist H, Axelsson H, Seashore-Ludlow B, Treyer A Matsson P, Lundbäck T, West A, et al. (2017) Prediction of intracellular exposure bridges the gap between target- and cell-based drug discovery. Proc Natl Acad Sci USA 114:E6231-E6239.

Mateus A, Matsson P, and Artursson P (2013) Rapid measurement of intracellular unbound drug concentrations. Mol Pharm 10:2467-2478.

Montgomery D (2001) Design and Analysis of Experiments, John Wiley \& Sons, Inc., New York Oballa RM, Belair L, Black WC, Bleasby K, Chan CC, Desroches C, Du X, Gordon R, Guay J, Guiral S, et al. (2011) Development of a liver-targeted stearoyl-CoA desaturase (SCD) inhibitor (MK-8245) to establish a therapeutic window for the treatment of diabetes and dyslipidemia. J Med Chem 54:5082-5096

Pfefferkorn JA (2013) Strategies for the design of hepatoselective glucokinase activators to treat type 2 diabetes. Expert Opin Drug Discov 8:319-330.

Pfefferkorn JA, Guzman-Perez A, Litchfield J, Aiello R, Treadway JL, Pettersen J, Minich ML, Filipski KJ, Jones CS, Tu M, et al. (2012) Discovery of (S)-6-(3-cyclopentyl-2-(4-(trifluoromethyl)-1H-imidazol-1-yl)propanamido)nicotinic acid as a hepatoselective glucokinase activator clinical candidate for treating type 2 diabetes mellitus. J Med Chem 55:1318-1333.

Read KD and Braggio S (2010) Assessing brain free fraction in early drug discovery. Expert Opin Drug Metab Toxicol 6:337-344.

Riccardi K, Cawley S, Yates PD, Chang C, Funk C, Niosi M, Lin J, and Di L (2015) Plasma protein binding of challenging compounds. J Pharm Sci 104:2627-2636.

Riccardi K, Li Z, Brown JA, Gorgoglione MF, Niosi M, Gosset J, Huard K, Erion DM, and Di L (2016) Determination of unbound partition coefficient and in vitro-in vivo extrapolation for SLC13A transporter-mediated uptake. Drug Metab Dispos 44:1633-1642.

Riccardi K, Lin J, Li Z, Niosi M, Ryu S, Hua W, Atkinson K, Kosa RE, Litchfield J, and Di L (2017) Novel method to predict in vivo liver-to-plasma Kpuu for OATP substrates using suspension hepatocytes. Drug Metab Dispos 45:576-580.

Riede J, Poller B, Huwyler J, and Camenisch G (2017) Assessing the risk of drug-induced cholestasis using unbound intrahepatic concentrations. Drug Metab Dispos 45:523-531.

Smith DA, Di L, and Kerns EH (2010) The effect of plasma protein binding on in vivo efficacy: misconceptions in drug discovery. Nat Rev Drug Discov 9:929-939.

Summerfield SG, Lucas AJ, Porter RA, Jeffrey P, Gunn RN, Read KR, Stevens AJ, Metcalf AC, Osuna MC, Kilford PJ, et al. (2008) Toward an improved prediction of human in vivo brain penetration. Xenobiotica 38:1518-1535.

Sun Y, Chothe PP, Sager JE, Tsao H, Moore A, Laitinen L, and Hariparsad N (2017) Quantitative prediction of CYP3A4 induction: impact of measured, free, and intracellular perpetrator concentrations from human hepatocyte induction studies on drug-drug interaction predictions. Drug Metab Dispos 45:692-705.

Tu M, Mathiowetz AM, Pfefferkorn JA, Cameron KO, Dow RL, Litchfield J, Di L, Feng B, and Liras S (2013) Medicinal chemistry design principles for liver targeting through OATP transporters. Curr Top Med Chem 13:857-866.

Walker E and Nowacki AS (2011) Understanding equivalence and noninferiority testing. J Gen Intern Med 26:192-196.

Address correspondence to: Li Di, Pharmacokinetics, Dynamics and Metabolism, Pfizer Inc., Eastern Point Road, Groton, CT 06340. E-mail: li.di@pfizer.com 